\title{
Contents of This Issue
}

\author{
Johannes Hebebrand \\ Department of Child and Adolescent Psychiatry, University of Duisburg-Essen, Essen, Germany
}

In the current issue of OBESITy FACTs, two original studies [1, 2] and a guideline of the Childhood Obesity Task Force of EASO [3] pertain to pediatric obesity. Two papers deal with surgical interventions (intragastric balloon and laparoscopic adjustable gastric banding) $[4,5]$. Three papers cover an intervention to reduce stigmatization [6], weight loss via whole body vibration [7] and the effect of animal versus soy protein in a high protein diet [8], respectively. The editorial written by Jocelin I. Hall (UK) [9] addresses the reluctance to treat due to both our currently limited understanding of obesity and negative attitudes to obese patients. The last section of this issue includes the 23 hot topic abstracts of the 17th European Congress on Obesity (ECO2009), Amsterdam, May 6-9, 2009 [10].

According to previous mostly population-based studies, many obese children underestimate their weight status. Rudolph et al. (Germany) [1] now report that clinically referred obese children perceived their weight status realistically. Most of their parents also correctly perceived the weight status of their children. Weight concerns were prominent among the obese children, particularly among the older 14- to 17-year-old group. Self-concept and self-worth were significantly reduced in obese versus co-assessed lean children. Compared to patients ascertained via the pediatric pulmonary disease outpatient clinic, the obese children more often depicted physical activities as their favorite activities ( 80 vs. $58.14 \%$ ). The ascertainment via the obesity outpatient clinic could very well be a plausible explanation for the largely correct perception of weight status by the patients themselves and their parents.

School settings have proven important for health behavior interventions; some have been shown to be effective in reducing childhood overweight. Based on the fact that the consumption of sugar-sweetened beverages had increased by $50 \%$ for boys and 33\% for girls between 1987 and 1998, Visscher et al. (The Netherlands) [2] designed an intervention study to reduce the consumption of such beverages. Six schools with a total of 5,866 pupils in the city of Zwolle (approximately 115,000 inhabitants) formed the intervention and control schools. The intervention consisted of placing water coolers in the canteen; additionally, free water bottles were handed out. The study took place between November 2006 and February 2007. The mean volume of water consumption per pupil per day was highest $(67 \mathrm{ml})$ at the start and dropped by almost $50 \%$ at the end of the intervention period. Sales of sugar-sweetened beverages did not differ between intervention and control schools. Over one third of the boys and one fourth of the girls consumed sugar-sweetened beverages at school every day; mean consumption of such beverages at school was almost $600 \mathrm{ml}$ for boys and $275 \mathrm{ml}$ for girls. Roughly $70 \%$ of the pupils reported no perceived impact of the free water coolers on the volume of beverages they drank. The results of the study are in line with other intervention studies that have shown little effect of the placement of water coolers in schools. The authors discuss that the timing of their pilot study during the winter months was not fortunate. Interestingly, the study had been requested by the Dutch ministry of health; the investigators suggest that the prioritized provision of free water at secondary school canteens to alternative health promotion interventions is reconsidered.

In their guideline [3], the Childhood Obesity Task Force of EASO provides practical tips for the treatment of overweight/ obese children for the primary health care provider. The focus is on history taking, categorization of obesity based on underlying causes and co-morbid disorders, physical and laboratory examinations, and provision of tips aiming to improve nutritional and physical activity habits of the obese child. The guideline specifically addresses setting realistic goals and expectations. The proposed treatment 'aims at changing behaviors of the child and his family to improve diet, physical activity and the quality of life'. In light of the well-documented difficulties of children and adolescents to lose weight in specific weight reduction programs, several guideline statements require thorough evaluation.

Intragastric balloon treatment for obesity is no longer in use in the USA because of complications of this procedure. According to the NICE guidelines (/www.nice.org.uk/nicemedia/pdf/CG43FullGuideline $5 b v . p d f$ ), gastric balloons are a short-term option; they were not considered as an appropriate surgical intervention in the long term. However, intragastric balloon treatment continues to be used in different parts of Europe. Peker et al. (Turkey) [4] treated 31 patients (19 females) with a mean age of approximately 35 years. The mean BMI was $42 \mathrm{~kg} / \mathrm{m}^{2}$ (range: $30-63 \mathrm{~kg} / \mathrm{m}^{2}$ ). Six months after placement, the mean BMI was $36.5 \mathrm{~kg} / \mathrm{m}^{2}$. The patients lost most of their weight during the first 3 months. Morbidly obese patients profited most. No major complications were observed during this study.

\section{KARGER}

Fax +497614520714

Information@Karger.de

www.karger.com
(C) 2010 S. Karger GmbH, Freiburg

Accessible online at:

www.karger.com/ofa
Prof. Dr. Johannes Hebebrand

Department of Child and Adolescent Psychiatry

University of Duisburg-Essen

Virchowstraße 174, 45147 Essen, Germany

Tel: +49 201 7227-465, Fax -302

johannes.hebebrand@uni-due.de 
What determines the conversion to gastric bypass after laparoscopic adjustable gastric banding (LAGB) in patients classified as having unsuccessfully lost weight after the initial procedure? Larsen et al. (The Netherlands) [5] selected those 34 of 113 LAGB patients classified as having had an unsuccessful weight outcome. 14 of these underwent conversion to gastric bypass after a mean of 48 months. Pre-gastric banding assessments of quality of life (QoL) were available for all 34 patients. In 24 patients, QoL scores were available at 6,12 and 24 months post banding. Patients with and without conversion did not differ significantly on pre-banding social and physical QoL, but the conversion group showed a worse pre-banding mental QoL. Repeated measures analyses of variance also revealed lower levels of mental health quality in the conversion group. In this first study to address QoL in relationship to conversion, the authors discuss that psychologically distressed patients may be more likely to seek additional surgical treatment or to accept conversion to gastric bypass when it is offered. Alternatively, patients with relatively good mental health might still deem themselves as capable of restricting food intake with help of the gastric band. Finally, the physician may offer gastric bypass as an additional intervention to those patients with a continuously poor mental health. Potentially, a preoperative algorithm can be developed to identify those patients that will profit more from a gastric bypass as the first intervention. Physicians should acknowledge that the mental health of the patient plays a role in the decision for conversion.

Anja Hilbert acted as the guest-editor of the recently published special issue of OBEsITy FACTS on stigmatization [11]. Rukavina et al. (USA) [6] now expand on this topic by reporting the results of an intervention study aimed at reducing both explicit and implicit bias of 42 kinesiology pre-professionals. 36 controls from other classes in the department did not receive the intervention. Three different questionnaires and the Implicit Association Test (IAT) were used. The intervention itself comprised both classroom and service learning components. The pre-professionals reported a strong implicit anti-fat bias before the intervention; similar to other studies, an overall explicit obesity bias was not detectable. The intervention was partially successful: Particularly weight control/blame significantly decreased between pre- and post-intervention. However, implicit bias as measured with the lazy/motivated or stupid/smart IAT scales did not change. Despite the considerable efforts to reduce bias within the context of the intervention, the respective effect sizes were relatively small. The authors discuss potential reasons underlying these small effect sizes and recommend further studies.

Physical exercise seems to play a role in the maintenance of weight loss. Vissers et al. (Belgium) [7] sought to examine the addition of resistance training to a diet to improve the different components of the metabolic syndrome; they particularly looked into whole body vibration (WBV). 79 subjects (20 males) with overweight or obesity entered the study and were randomized into three intervention groups: a diet only group, a diet plus fitness training group and a diet plus WBV group. A control group consisted of 21 overweight and obese adults, who were also recruited via media advertising. A BMI $>40 \mathrm{~kg} / \mathrm{m}^{2}$ served as an exclusion criterion. WBV was performed as a group training on a WBV platform. A total of 18 subjects $(22.8 \%)$ dropped out of the study, 8 of these were from the diet group. 5 individuals dropped out of the vibration group. After 12 months, the vibration group had the largest loss of visceral adipose tissue. In addition, the vibration group was the only group with a weight loss in excess of $10 \%$ at 6 months, which was maintained at 12 months. The authors acknowledge the small group sizes as a limitation of their 12-month study. They recommend further studies into the potentially positive effects of WBV.

Tan and co-workers (Australia) [8] compared the effects of high-protein meals based on meat, dairy and soy sources in a crossover feeding trial encompassing 12 adults. During the trial, energy expenditure, substrate oxidation and satiety levels were determined during 8-hour stays in a whole room calorimeter. Irrespective of the protein source, $30 \%$ of the energy content of the diet was based on proteins, $40 \%$ on carbohydrates and $30 \%$ on fat. The protein source had no effect on energy expenditure, carbohydrate or fat oxidation. Protein oxidation, however, was lower in meals with predominantly meat compared to soy sources. High-protein meals based on animal protein may be beneficial in terms of retaining lean body mass.

\section{References}

1 Rudolph H, Blüher S, Falkenberg C, Töpfer M, Körner A, Würz J, Kiess W, Brähler E: Perception of body weight status: a case control study of obese and lean children and adolescents and their parents. Obes Facts 2010;3(2):83-91.

$\checkmark 2$ Visscher TLS, van Hal WCW, Blokdijk L, Seidell JC, Renders CM, Bemelmans WJE: Feasibility and Impact of placing water coolers on sales of sugarsweetened beverages in Dutch secondary school canteens. Obes Facts 2010;3(2):109-115.

$\checkmark 3$ Baker JL, Farpour-Lambert NJ, Nowicka P, Pietrobelli A, Weiss R: Evaluation of the overweight/obese child - practical tips for the primary health care provider: Recommendations from the Childhood Obesity Task Force (COTF) of the European Association for the Study of Obesity (EASO). Obes Facts 2010;3(2):131-137.
4 Peker Y, Durak E, Ozgurbuz U: Intragastric balloon treatment for obesity: prospective single center study findings. Obes Facts 2010;3(2):105-108.

5 Larsen JK, Zijlstra H, Van Ramshorst B, Geenen $\mathrm{R}$ : Conversion to gastric bypass in patients with unsuccessful weight loss after gastric banding may depend on mental quality of life. Obes Facts 2010;3(2):127-130.

6 Rukavina P, Li W,Shen B, Sun H: A Service Learning Based Project to Change Implicit and explicit bias toward obese individuals in kinesiology pre-professionals. Obes Facts 2010;3(2):117-126.

7 Vissers D, Verrijken A, Mertens I, Van Gils C, Van de Sompel A, Truijen S, Van Gaal L: Effect of long-term whole body vibration training on visceral adipose tissue: a preliminary report. Obes Facts 2010;3(2):93-100.
8 Tan SY, Batterham M, Tapsell L: Energy expenditure does not differ, but protein oxidation rates appear lower in meals containing predominantly meat versus soy sources of protein. Obes Facts 2010;3(2):101-104.

9 Hall JI: Obesity - a reluctance to treat? Obes Facts 2010;3(2):79-80.

10 ECO2009 Hot Topic Abstracts. 17th European Congress on Obesity (ECO2009), Amsterdam, the Netherlands, May 6-9, 2009. Obes Facts 2010; 3(2):139-146.

11 Hilbert A (ed): The Burden of Burden: Current Advances in Weight Stigma Research. Obes Facts 2010;3(1):1-76. 